\section{Commentary: Functional coronary artery stenosis-How can we functionally apply this to the operating room?}

\author{
Alison F. Ward, MD, and Richard Lee, MD, JD, MBA
}

In this edition of the Journal, Hwang and colleagues ${ }^{1}$ studied graft patency rates at 1 and 5 years after coronary artery bypass grafting (CABG). Preoperatively, the functional significance of coronary artery stenosis was evaluated using single-photon emission computed tomography and the degree of coronary stenosis was classified as either intermediate $(70 \%-90 \%)$ or severe $(\geq 90 \%)$. At 1 and 5 years, graft occlusion rates were greater in functionally insignificant stenosis compared with functionally significant and in intermediate stenosis as compared with severe stenosis.

It should be noted that all of the patients in this study underwent off-pump CABG with a Y composite graft using a left internal mammary artery (IMA) and right IMA (14\%) or left IMA and saphenous vein graft $(86 \%)$. The average Society of Thoracic Surgeons risk score was 1.2, and the average ejection fraction was $57 \%$. Although this limits the broad applicability of the study's findings, it does provide fewer confounding variables for graft failure due to the limited grafting strategies and a low-risk patient population.

In this manuscript, the authors fail to address the significant effect coronary artery territory has on graft failure. There was an odds ratio of occlusion of 6.11 and 14.88 for the left circumflex and right coronary artery, respectively, as compared with the left anterior descending. Was there a difference in the type of graft used or a difference in the degree or significance of stenosis that would cause such a difference in the odds ratio of occlusion for these 2

\footnotetext{
From the Division of Cardiothoracic Surgery, Department of Surgery, Medical College of Georgia, Augusta University, Augusta, Ga.

Disclosures: The authors reported no conflicts of interest.

The Journal policy requires editors and reviewers to disclose conflicts of interest and to decline handling or reviewing manuscripts for which they may have a conflict of interest. The editors and reviewers of this article have no conflicts of interest.

Received for publication Dec 7, 2020; revisions received Dec 7, 2020; accepted for publication Dec 8, 2020; available ahead of print Jan 7, 2021.

Address for reprints: Richard Lee, MD, JD, MBA, Department of Surgery, Medical College of Georgia, 1120 15th St, BA-4300, Augusta, GA 30912 (E-mail: richardleemdmba@gmail.com or RICKLEE@augusta.edu).

J Thorac Cardiovasc Surg 2021;161:1019-20

$0022-5223 / \$ 36.00$

Copyright (C) 2020 by The American Association for Thoracic Surgery

https://doi.org/10.1016/j.jtcvs.2020.12.025
}

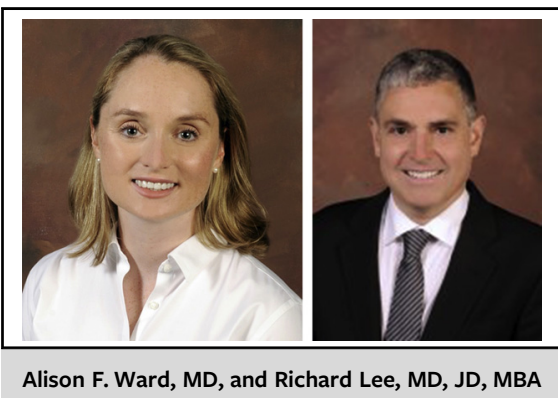

CENTRAL MESSAGE

Graft patency is better at 5 years in functionally significant and severe stenosis but how should this guide our operative decisionmaking and how does it affect long-term survival for these patients?

territories? In addition, in that same model, the type of conduit did not have an effect on graft occlusion. While the authors cite the SAVE RITA (Saphenous Vein Versus Right Internal Thoracic Artery as a Y-Composite Graft) trial $^{2}$ in support of that finding, there are numerous other studies demonstrating improved patency of bilateral IMAs over saphenous vein grafts. ${ }^{3-6}$

The authors conclude that in a difficult CABG, surgeons may consider skipping lesions of moderate, functionally insignificant stenosis because of the $14 \%$ graft failure rate. We would caution the authors with that statement and propose the opposite-with an $86 \% 5$-year patency rate, even a moderate, functionally insignificant stenosis should be attempted. Forgoing a graft at potentially greater risk of occlusion risks a bigger problem of under-revascularizing the patient. After all, CABG provides the patient with the best chance complete revascularization and improved survival.

In this study, Hwan and colleagues assessed graft failure rate 5 years after $C A B G$ and demonstrate that failure rates are greater when the target vessel is moderately stenotic as compared with severely stenotic and a functionally insignificant stenosis as compared with functionally significant. The one glaring omission with these findings is the effect of graft failure on survival. If we are to change practice in regards to which coronary anastomoses we perform and which we skip due to poor graft patency, there needs to be a demonstrated survival benefit. We commend the authors on this study and encourage them to look at long-term survival in addition to graft patency in this cohort of patients. 


\section{References}

1. Hwang H, Paeng JC, Kang J, Jang M-J, Kim K-B. Relation between functional coronary artery stenosis and graft occlusion after coronary artery bypass grafting. J Thorac Cardiovasc Surg. 2021;161:1010-8.e1.

2. Kim KB, Hwang HY, Hahn S, Kim JS, Oh SJ. A randomized comparison of the saphenous vein versus right internal thoracic artery as a Y-composite graft (SAVE RITA) trial: one-year angiographic results and mid-term clinical outcomes. J Thorac Cardiovasc Surg. 2014;148:901-7; discussion 907-8.

3. Fukui T, Tabata M, Manabe S, Shimokawa T, Morita S, Takanashi S. Angiographic outcomes of right internal thoracic artery grafts in situ or as free grafts in coronary artery bypass grafting. J Thorac Cardiovasc Surg. 2010;139:868-73.
4. Gansera B, Schmidtler F, Angelis I, Kiask T, Kemkes BM, Botzenhardt F. Patency of internal thoracic artery compared to vein grafts-postoperative angiographic findings in 1189 symptomatic patients in 12 years. Thorac Cardiovasc Surg. 2007;55:412-7.

5. Sabik JF III, Lytle BW, Blackstone EH, Houghtaling PL, Cosgrove DM Comparison of saphenous vein and internal thoracic artery graft patency by coronary system. Ann Thorac Surg. 2005;79:544-51; discussion 54451.

6. Tatoulis J, Buxton BF, Fuller JA. The right internal thoracic artery: the forgotten conduit-5,766 patients and 991 angiograms. Ann Thorac Surg. 2011;92:9-15; discussion 15-7.
See Article page 1010.

\section{Commentary: Y bother?}

Aaron Bettenhausen, MD, and

Edward Y. Sako, MD, PhD

In this edition of the Journal, Hwang and colleagues ${ }^{1}$ explored the impact of severity and significance of coronary artery stenosis on graft patency following coronary artery bypass grafting. Specifically, they sought to determine the impact of functional significance of the stenosis compared with the angiographically determined degree of stenosis. To determine functional significance, they used myocardial single-photon emission computed tomography (SPECT).

During the 5-year study period, 295 patients underwent off-pump coronary artery bypass grafting with composite y-grafts (42 right internal thoracic artery and 253 saphenous vein) based off an in situ left internal thoracic artery for an average of 3.5 distal anastomoses per patient. A total of 1031 anastomoses were then surveilled at 1 and 5 years via either standard or multidetector computed tomography angiography. The authors found that lack of functional ischemia, particularly in arteries with less than severe $(90 \%)$ stenosis, was a risk factor for graft occlusion. ${ }^{1}$

From the Department of Cardiothoracic Surgery, University of Texas Health Science Center at San Antonio, San Antonio, Tex.

Disclosures: E.Y.S. has a financial relationship with Medtronic, Inc. A.B. reported no conflicts of interest.

The Journal policy requires editors and reviewers to disclose conflicts of interest and to decline handling or reviewing manuscripts for which they may have a conflict of interest. The editors and reviewers of this article have no conflicts of interest.

Received for publication Dec 2, 2020; revisions received Dec 2, 2020; accepted for publication Dec 3, 2020; available ahead of print Dec 17, 2020.

Address for reprints: Edward Y. Sako, MD, PhD, Department of Cardiothoracic Surgery, University of Texas Health Science Center at San Antonio, Mail Code 7841, 7703 Floyd Curl Dr, San Antonio, TX 78229-3900 (E-mail: sako@uthscsa.edu).

J Thorac Cardiovasc Surg 2021;161:1020-1

$0022-5223 / \$ 36.00$

Copyright (c) 2020 by The American Association for Thoracic Surgery

https://doi.org/10.1016/j.jtcvs.2020.12.031
Check for updates

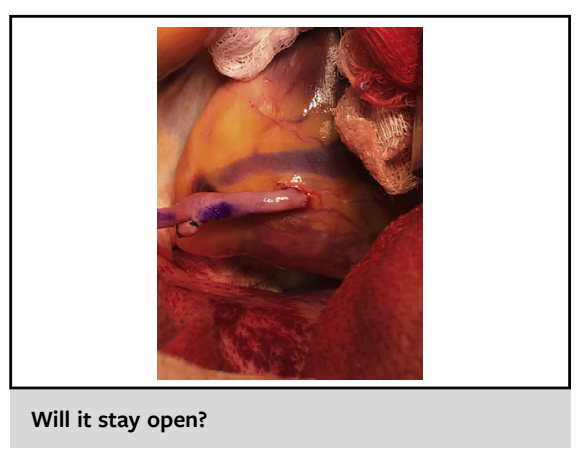

CENTRAL MESSAGE

Understanding the severity and significance of coronary artery stenosis may eventually help guide surgical revascularization strategies.

Advancing technologies, such as fractional flow reserve, are now helping guide coronary interventions. Understanding the importance of not only the anatomic degree of coronary stenosis but also the physiologic degree of stenosis has made a large impact on the decision-making process of percutaneous coronary intervention. ${ }^{2,3}$ How this information translates to bypass graft patency is not entirely clear, as the concept of competitive flow is an issue solely limited to surgical revascularization.

Composite configurations and use of sequential grafts have not clearly been shown to be inferior with regards to patency rates. ${ }^{4}$ However, use of such grafts complicates the issue of competitive flow and factors that may lead to graft occlusion. This limits what useful information can be extracted from this study, as these configurations may introduce the potential for competition in flow not only 